\title{
Survey on Performance Analysis of AODV, DSR and DSDV in MANET
}

\author{
Kedir Lemma Arega \\ School of Technology and Informatics, Ambo University \\ Gemeda Raga \\ College of Informatics, Bule Hora University \\ Roba Bareto \\ School of Technology and Informatics, Ambo University
}

\begin{abstract}
Routing is a crucial issue in MANET due to the absence of fixed infrastructure and centralized administration. Many routing protocols like Ad-hoc On-demand Distance Vector (AODV), Dynamic Source Routing (DSR), and Destination Sequenced Distance Vector (DSDV) have been proposed to find the optimized path from source node to destination nodes. This paper analyzed the performance of AODV, DSR and DSDV on the basis of sent packets, received packets and Quality of Service (QoS) metrics like throughput, end to end delay, packet delivery ratio, packet loss ratio with varying network load and network size.
\end{abstract}

Index Terms: AODV, DSR, DSDV, QoS, Routing Protocols.

DOI: $10.7176 / \mathrm{CEIS} / 11-3-03$

Publication date:May $31^{\text {st }} 2020$

\section{Introduction}

Mobile Ad-hoc Networks (MANETs) are self-configuring networks consisting of mobile nodes that are communicating through wireless links. There is a cooperative engagement of a collection of mobile nodes without the required intervention of any centralized access point or existing infrastructure. The nodes move arbitrarily; therefore, the network may experience unpredictable topology changes. It means that a formed network can be deformed on the fly due to mobility of nodes. Hence, it is said that an ad-hoc wireless network is self-organizing and adaptive. Due to infrastructure less and self-organizing nature of ad-hoc networks, it has several applications in the area of commercial sector for emergency rescue operations and disaster relief efforts. MANETs also provides a solution in the field of military battlefield to detect movement of enemies as well as for information exchange among military headquarters and so on (A. A. Chavana, 2016). Also, MANET provides an enhancement to cellular based mobile network infrastructure. Nowadays, it is an inexpensive alternative for data exchange among cooperative mobile nodes (Aggarwal, 2014).

For communication among two nodes, one node has to check that the receiving node is within the transmission range of source (Range of a node is defined with the assumption that mobile hosts uses wireless RF transceivers as their network interface), if yes, then they can communicate directly otherwise, with the help of intermediate nodes communication will take place. Each node will act as a host as well as a router. All the nodes should be cooperative so that exchange of information would be successful. This cooperation process is called as routing (Ahmed Al-Maashri, 2006) (Akshai Aggarwal, 2011).

Due to the presence of mobility, the routing information will have to be changed to reflect changes in link connectivity. There are several possible paths from source to destination. The routing protocols find a route from source to destination and deliver the packet to correct destination. The performance of MANETs is related to efficiency of the MANETs routing protocols (Akshay Shankar, Performance Comparison of AODV, DSR, DSDV and OLSR MANET Routing Protocols, 2016) and the efficiency depends on several factors like convergence time after topology changes, bandwidth overhead to enable proper routing, power consumption and capability to handle error rates.

There are multiple hops between the routes of two nodes through other nodes in the network. That's why searching efficient routes at the network layer and improving QoS at the transport layer in MANETs is very challenging work.

The point of this paper is to access the best exertion of proactive and reactive routing communication protocols AODV, DSR, DSDV on the basis of QoS frameworks like throughput, delay, packet delivery ratio (PDR), packet loss ratio (PLR) by changing network load and network size. This work can give inspiration to additionally look into enhancing the present conventions or potentially make new ones to address the difficulties in MANETs.

The organization of the paper is as per the following: Section 2 discusses the routing protocols in MANETs. Further, there is a complete depiction of related work in Section 3. An overview and general comparison of the 
three main ad hoc routing protocols AODV, DSR, DSDV present in section 4. The simulation environment and performance metrics are described in Section 5 along with simulation results. Section 6 concludes the paper and presents future work.

\section{MANET Routing Protocols}

An ad-hoc routing protocol controls the routing of packet in MANET. In MANET, initially nodes are not aware of topology of network, they need to discover that. An ad-hoc routing protocol can be classified in reactive (ondemand), proactive (table-driven) protocol, hybrid protocol. The figure 1 shows the prominent way of classifying MANETs routing protocols. The protocols may be categorized into two types, Proactive and Reactive.

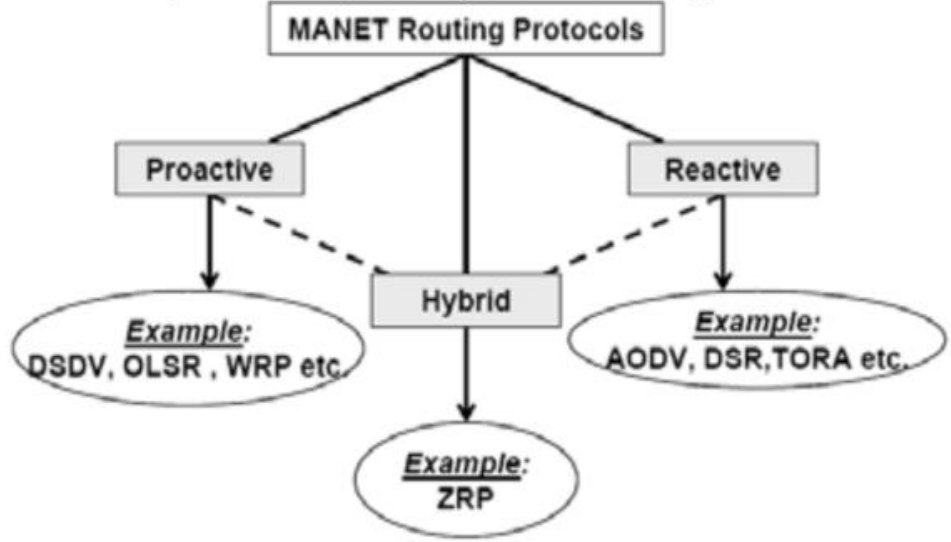

Figure 1. Routing protocols in MANET

\subsection{Proactive (table-driven) Routing Protocol}

The proactive routing is table-driven routing protocol. In this routing protocol, routing information is broadcasted by mobile nodes to the neighbors. Each node needs to keep their routing table which contains the information of neighborhood nodes, reachable nodes and the number of hops. In other words, all of the nodes have to find their nodes in the neighborhood as there is change in network topology. Therefore, the disadvantage of this protocol is when size of network increases, then overhead increases. The most familiar proactive type is destination sequenced distance vector (DSDV) routing protocol.

\subsubsection{Destination-Sequenced Distance-Vector (DSDV) Protocol}

Destination-Sequenced Distance-Vector (DSDV) Protocols i.e. Table-driven DSDV protocol which is a modification in the Distributed Bellman-Ford (DBF) Algorithm which was used successfully in many of the dynamic packet switched networks. In case of DSDV, every node in the mobile network is required to send a sequence number, which is periodically increased by two and it is transmitted along with other routing update messages to all other neighboring nodes.

\subsection{Reactive (on-demand) routing protocol}

This type of protocol finds routes by using the route request packet. It is a bandwidth efficient on-demand routing protocol for Mobile Ad-Hoc Networks. The protocol deals with two main functions of Route Discovery and Route Maintenance. The discovery of new route is decided by Route Discovery function and the detection of link breaks and repair of an existing route is decided by Route Maintenance function. Reactive or on-demand routing protocols route is discovered when required. Distribution of information is not required in reactive protocols. One of the reactive protocols is AODV. These protocols do not maintain permanent route table. Instead, routes are built by the source on demand.

\subsubsection{Ad Hoc On-demand Distance Vector Routing (AODV) protocol}

AODV is Ad-hoc On-Demand Distance Vector Routing protocol. In AODV, route establishment takes place only when there is a demand for new route. AODV is capable of unicast, broadcast and multicast routing. AODV is able to react quickly to the changes in the network topology and it updates only the hosts that may be affected by the changes in the network by using the RREQ message. The RREQ and RREP messages are responsible for the route discovery.

\subsubsection{Dynamic Source Routing (DSR)}

Dynamic Source Routing is a Pure On-Demand routing protocol, where the route is calculated only when it is necessary. It is designed for use in multi hop ad hoc networks of mobile nodes. DSR allows the network to be selforganized and self-configured without any central administration and network setup. It uses no periodic routing messages like AODV, thus reduces bandwidth overhead and conserved battery power and also huge routing 
updates. It needs only the effort from the MAC layer to identify link failure's uses source routing where the whole route is carried as an overhead.

In DSR, the whole route is carried with the message as an overhead, whereas in AODV, the routing table is maintained thus it is not required to send the whole route with the message during the Route Discovery process.

\section{Related Works}

A large number of papers try to simulate or analyze reactive and proactive protocols in general. The problem of analytical approaches lies in the fact that protocols like DSR, DSDV and AODV are complex and can be configured in many ways to achieve high performance in various scenarios. In this section we list the prior work done in of protocol comparison in ad-hoc environment.

Although several routing protocols have been proposed that can be used in mobile ad hoc networks, there is very little formal analysis that considers the communication overhead or in other word routing overhead for these procedures.

(Mohammad Naserian, 2017) provides a new mathematical framework for quantifying the overhead of reactive routing protocols such as Dynamic Source Routing (DSR) and Ad hoc On-Demand Distance Vector Routing (AODV) in wireless ad hoc networks with random location of the nodes. The analysis is compared with the simulations and found to match with the simulation results. The result of this study can be used to predict scalability properties of routing protocols.

Mobile Ad hoc system is system where hubs impart with no focal organization or system framework. They are associated by means of remote channels and can utilize different bounces to trade information. Directing conventions are required for correspondence in such Ad hoc arranges where it focuses for proficient and opportune conveyance of message. There are different execution measurements to think about Ad hoc directing conventions. In this paper Amith Khandakar et al. [13] show a well-ordered method is expressed to analyze 3 famous routing conventions, DSR, AODV and DSDV in view of execution measurements Packet Delivery Fraction (Pdf), End to end postpone and Normalized Routing load while changing the quantity of hubs, speed and Pause time. It additionally gives a well-ordered approach in view of presumption on the best way to do such a similar review, which could be utilized for future research.

(J. Broch, 1998) evaluate the performance of multiple routing protocols (AODV, DSR, OLSR and DSDV) based on PDR and routing overhead. They analyzed through experiment that Temporally Ordered Routing Algorithm gives the worst performance in terms of routing overhead and AODV outperforms DSR in terms of routing overhead whereas the other performance metrics of AODV and DSR are almost same at all mobility rates.

(Akshay Shankar, Performance Comparison of AODV, DSR, DSDV and OLSR MANET Routing Protocols, 2016) analyzed the performance of well-known MANETs routing protocol in high mobility case under low, medium and high-density scenario. They have analyzed with respect to Average End-to-End Delay, Normalized Routing Load (NRL), Packet Delivery Fraction (PDF) and Throughput. Simulation results verify that AODV gives better performance as compared to DSR and DSDV.

(Samir R. Das, 2014) presented the performance studies between two reactive routing protocols AODV and DSR for ad hoc networks by changing network load, mobility, and network size. They evaluated AODV and DSR on the basis of PDR. They observed that DSR performs better than AODV in smaller network size, lower load and lower mobility whereas it is not true in larger network size, more load and higher mobility. The routing load generated by DSR is less than AODV.

(A. A. Chavana, 2016) have analyzed AODV and DSDV in terms of routing overhead, packet delivery ratio, throughput and end to end delay. The performance of AODV is better than DSDV in terms of throughput, packet delivery ratio and routing overhead.

(Ahmed Al-Maashri, 2006) assessed the execution of AODV, DSR and OLSR in the existence of self-similar traffic. They have considered throughput, PDR, delay, and routing overhead as QoS performance metrics. The simulation results showed that the performance of DSR is better in terms of above motioned QoS performance metrics at a speed less than $10 \mathrm{~m} / \mathrm{s}$.

(Bhavyesh Divecha, 2014) accessed the execution of AODV and DSR routing protocols by varying node density and hop count. Simulation results showed that DSR gives a better result than DSDV for all scenarios such as varying network node, varying hop count, changing speed on different mobility models.

(V. Rajeshkumar, 2015) has presented a performance comparison and study of reactive and proactive protocols AODV, DSR and DSDV based on metrics such as throughput, control overhead, packet delivery ratio and average end-to-end delay

Sajjad Ali and Asad Ali, have analyzed performance of AODV, DSR, and OLSR routing protocols by three metrics: delay, network load and throughput. They identified the best routing protocols for Mobile Ad-hoc Network.

(Sandeep Sharma, 2017) has attempted to compare three well known routing protocols Ad-hoc on-demand distance vector (AODV), Dynamic Source Routing (DSR) and Destination Sequenced Distance Vector (DSDV) 
by using three presentation metrics packet delivery ratio (PDR), Routing Overhead and Remain Energy by using the NS-2.34 simulator.

(Fahad Taha AL-Dhief, 2017) has presented the performance comparison between Dynamic Source Routing (DSR), Ad hoc on demand distance Vector Routing (AODV) as reactive routing protocols and Destination Sequenced Distance Vector (DSDV) as a proactive routing protocol to precisely determine which protocol is more effective. They simulated and evaluated the performance of these protocols in terms of the packet delivery ratio, average throughput, average end-to-end delay, and packet loss ratio with respect to the variable number of nodes.

(Ankita Sharma, 2014) has presented the performance of AODV, DSR and DSDV MANET protocols for different number of nodes and mobility with different traffic channels CBR and FTP. They considered performance metrics such as packet delivery ratio, throughput and average end-to-end delay.

(Akshay Shankar, 2016) have evaluated the performance of AODV, DSDV, DSR and OLSR based on Packet Delivery Ratio, Throughput and Average end-to-end delay. They dictated the simulation results that OLSR and DSDV perform best in networks where nodes were less mobile and densely populated. AODV was suitable for networks with a greater number of nodes. DSR performed well in networks with low mobility rate and a lower traffic density.

(Nilesh Chandra, 2015) has compared the performance of above three mentioned routing protocols on the basis of various parameters such as throughput, delay and packet delivery ratio. Make the observations about how the performance of these routing protocols can be improved.

(Asma Tuteja, 2010) has compared the performance of AODV, DSDV, and DSR protocols together and individually too. The performance matrix includes PDR (Packet Delivery Ratio), Throughput, End to End Delay, Routing overhead. They also compared the performance of routing protocols when packet size changes, when time interval between packet sending changes, when mobility of nodes changes.

(Gulati, 2014) compared AODV, DSR and DSDV by varying mobility speed, network load and data rate. They have considered PDR, delay and jitter as performance metrics. The simulation result showed that AODV outperforms the other routing algorithms.

(Kumar, 2016) performed the comparison between AODV, DSR and DSDV over three metrics throughput, packet loss and packet received. They have concluded that the overall execution of DSR is superior to AODV and DSDV. Table I shows the summery of the related works to evaluating the performance of the routing protocols.

This paper assesses the most common protocols like AODV, DSR and DSDV based on QoS metrics (throughput, delay, PDR and PLR) by varying network load and network size.

\begin{tabular}{|c|c|c|c|c|c|c|c|c|}
\hline Sno. & $\begin{array}{l}\text { Authors, } \\
\text { Year }\end{array}$ & $\begin{array}{l}\text { Compared } \\
\text { Protocols }\end{array}$ & $\begin{array}{ll}\text { QoS } & \text { Metrics } \\
\text { Considered } & \end{array}$ & $\begin{array}{l}\text { Simulator } \\
\text { used }\end{array}$ & $\begin{array}{l}\text { Movement } \\
\text { model }\end{array}$ & Area & \#Nodes & Remarks \\
\hline 1 & $\begin{array}{l}\text { J.Broch, } \\
1998\end{array}$ & $\begin{array}{l}\text { AODV, } \\
\text { DSR, } \\
\text { OLSR and } \\
\text { DSDV }\end{array}$ & $\begin{array}{lr}\bullet & \text { Packet } \\
\text { Delivery } & \\
\text { Ratio } & \\
\bullet & \text { Routing } \\
\text { Overhead } & \\
\text { Optimality } & \text { Path }\end{array}$ & NS2 & $\begin{array}{l}\text { Random } \\
\text { Waypoint }\end{array}$ & $\begin{array}{l}1500 * 300 \\
\text { sq. } \mathrm{m}\end{array}$ & 50 & $\begin{array}{l}\text { - TORA } \\
\text { gives the worst } \\
\text { performance in terms of } \\
\text { routing overhead. } \\
\text { The routing } \\
\text { overhead of AODV } \\
\text { outperforms DSR } \\
\text { whereas the other } \\
\text { performance metrics of } \\
\text { AODV and DSR are } \\
\text { almost the same. }\end{array}$ \\
\hline 2 & $\begin{array}{l}\text { Akshay } \\
\text { Shankar, } \\
2016\end{array}$ & $\begin{array}{l}\text { AODV, } \\
\text { DSR, } \\
\text { DSDV, } \\
\text { OLSR }\end{array}$ & $\begin{array}{l}\text { - Average } \\
\text { End-to-End Delay } \\
\text { - } \quad \text { Normalized } \\
\text { Routing Load (NRL) } \\
\text { - Packet } \\
\text { Delivery Fraction } \\
\text { (PDF) and } \\
\text { - }\end{array}$ & NS-3.25 & $\begin{array}{l}\text { Random } \\
\text { Waypoint }\end{array}$ & $500 \times 2000 \mathrm{~m}$ & $\begin{array}{l}20,60 \\
100\end{array}$ & $\begin{array}{l}\text { OLSR and } \\
\text { DSDV perform best in } \\
\text { networks where nodes } \\
\text { were less mobile and } \\
\text { densely populated. } \\
\text { AODV was } \\
\text { suitable for networks } \\
\text { with a greater number } \\
\text { of nodes }\end{array}$ \\
\hline 3 & $\begin{array}{l}\text { M. Gulati } \\
\text { and } \\
\text { K. } \\
\text { Kumar, } \\
2014\end{array}$ & $\begin{array}{l}\text { AODV, } \\
\text { DSR, } \\
\text { DSDV }\end{array}$ & $\begin{array}{ll}\bullet & \text { PDR } \\
\bullet & \text { Delay } \\
\bullet & \text { Throughput } \\
\text { - } & \text { Jitter }\end{array}$ & NS-2 & $\begin{array}{l}\text { Random } \\
\text { Waypoint }\end{array}$ & $\begin{array}{ll}1000 & * 1000 \\
\text { sq.m } & \end{array}$ & $20-100$ & $\begin{array}{l}\text { AODV outperforms the } \\
\text { other routing } \\
\text { protocols }\end{array}$ \\
\hline 4 & $\begin{array}{l}\text { M.Gupta } \\
\text { and S. } \\
\text { Kumar, } \\
2015\end{array}$ & $\begin{array}{l}\text { AODV, } \\
\text { DSR, } \\
\text { DSDV }\end{array}$ & $\begin{array}{ll} & \text { Packet } \\
\text { Loss } & \\
\text { - } & \text { Packet } \\
\text { receives } & \\
\bullet & \text { Throughput }\end{array}$ & NS-2 & $\begin{array}{l}\text { Random } \\
\text { waypoint }\end{array}$ & $\begin{array}{l}600 \\
600 \text { sq.m }\end{array}$ & 100 & $\begin{array}{l}-\quad \text { DSR has } \\
\text { minimum packet loss } \\
\text { than AODV \& DSDV }\end{array}$ \\
\hline
\end{tabular}

Table I Summary of the related works to evaluate the performance of the routing communications protocol 


\section{Overview of AODV, DSR and DSDV}

\subsection{Overview of AODV}

AODV is one of the most popular routing protocols, which is a simple and efficient on-demand MANET routing protocol (Azad, 2006). The concepts of AODV that makes it desirable for MANETs with limited bandwidth include the following:

* Minimal space complexity: The algorithm makes sure that the nodes that are not in the active path do not maintain information about this route. After a node receives the RREQ and sets a reverse path in its routing table and propagates the RREQ to its neighbors, if it does not receive any RREP from its neighbors for this request, it deletes the routing info that it has recorded.

* Maximum utilization of the bandwidth: This can be considered the major achievement of the algorithm. As the protocol does not require periodic global advertisements, the demand on the available bandwidth is less. And a monotonically increased sequence number counter is maintained by each node in order to supersede any stale cached routes. All the intermediate nodes in an active path updates their routing tables also make sure of maximum utilization of the bandwidth. Since, these routing tables will repeatedly be used if that intermediate node receives any RREQ from another source for the same destination. Also, any RREPs that are received by the nodes are compared with the RREP that was propagated last using the destination sequence numbers and are discarded if they are not better than the already propagated RREPs.

* Simple: It is simple with each node behaving as a router, maintaining a simple routing table, and the source node initiating path discovery request, making the network self-starting.

* Most effective routing info: After propagating a RREP message, if a node receives RREP with smaller hop-count, it updates its routing info with this better path and propagates it.

* Most current routing info: The route info is obtained on demand. Also, after propagating an RREP, if a node receives RREP with greater destination sequence number, it updates its routing info with this latest path and propagates it.

* Loop-free routes: The algorithm maintains loop-free routes by using the simple logic of nodes discarding the packets for same broadcast-id.

* Coping up with dynamic topology and broken links: When the nodes in the network move from their places and the topology is changed, or the links in the active path are broken, the intermediate node that discovers this link breakage propagates an RERR message. And the source node re-initializes the path discovery if it still desires the route. This ensures quick response to broken links.

* Highly Scalable: The algorithm is highly scalable because of the minimum space complexity and broadcasts avoided.

\subsection{Overview of DSR}

DSR is a loop-free, on-request (reactive) routing protocol that relies upon source routing [18]. It is a self-organizing and self-configuring method. DSR doesn't utilize intermittent updates as it computes routes when there is a need and after that keep up them. In this approach, the sender decides the total sequence of nodes through which the packet needs to travel, the sender attaches this route records in the packet's header. There are three phases of DSR protocol:

i. Route Discovery

ii. Route cache

iii. Route Maintenance.

DSR gives incredible execution for routing in ad-hoc networks with no infrastructure or administration. Nodes forward packets for one another to permit communication among them. It also reacts rapidly to changes in the network having very low overhead.

\subsection{Overview of DSDV}

This algorithm uses routing table like Distance vector but each routing table entry is tagged with sequence number, generated by destination. To maintain consistency among routing tables in a dynamically varying topology, updates are transmitted periodically. Each mobile station advertises its own routing table to its current neighbors (Akshai Aggarwal, 2011).

Routing information is advertised by broadcasting or multicasting. Packets are transmitted periodically and incrementally as changes are detected. In a wireless medium broadcast are limited by the physical characteristic of medium. If a node invalidates its entry to a destination due to loss of next hop node, it increments its sequence number and uses new sequence number in its next advertisement of the route. Data broadcast by each mobile computer will contain new sequence number and
i.
Destination IP address 
ii. Number of hops required to reach the destination

iii. Sequence number of the information received regarding that destination

To reduce the information carried in each broadcast message, two methods exist

i. $\quad$ Full dump: The dump carries all the available routing information

ii. Incremental carry: The message carries only changed information since the last full dump.

It may happen that every time a mobile host receives a worse metric than the upcoming sequence number update. In that case, route to the destination may change at every new sequence number. Solution to this problem is to delay the advertisement if mobile host can determine that a route with a better metric is likely to show up soon. For this two routing tables are maintained, one for forwarding packets and the other for incremental routing information packets. DSDV guarantees a loop free path to each destination without requiring nodes to participate in any complex update coordination protocol. In this protocol, routing tables of each node can be visualized as forming $\mathrm{N}$ trees, one rooted at each destination (Akshai Aggarwal, 2011). DSDV is one of the early algorithms available and the main advantage of this protocol is that it is quite suitable for creating ad hoc networks with a small number of nodes. One of the disadvantages of this protocol is that it requires a regular update of its routing tables, which uses up battery power and some amount of bandwidth, even when the network is idle. Secondly, whenever the topology of the network changes, a new sequence number is necessary before the network reconverges. Thus, DSDV is not suitable for highly dynamic networks. Table II shows the Comparative analysis of AODV, DSR and DSDV.

\begin{tabular}{|c|c|c|c|c|}
\hline Sno. & Parameters & AODV & DSR & DSDV \\
\hline 1 & Routing Type & Reactive & Reactive & Proactive \\
\hline 2 & Route Selection & Shortest \& update path & Shortest \& update path & Shortest \& update path \\
\hline 3 & Multiple Route & No & Yes & No \\
\hline 4 & Routing Structure & Flat Structure & Flat Structure & Flat Structure \\
\hline 5 & Suited for & $\begin{array}{l}\text { Well suited for large } \\
\text { network }\end{array}$ & $\begin{array}{l}\text { Well suited for large } \\
\text { network }\end{array}$ & $\begin{array}{l}\text { Some dynamic small } \\
\text { networks }\end{array}$ \\
\hline 6 & Multicasting & Yes & No & Yes \\
\hline 7 & $\begin{array}{l}\text { Congestion } \\
\text { Handling }\end{array}$ & Yes & No & Yes \\
\hline 8 & Route maintain in & Route table & Route cache & Route table \\
\hline 9 & $\begin{array}{l}\text { Updates Transmitted } \\
\text { to }\end{array}$ & Source & Source & Neighbor \\
\hline 10 & QoS Support & No & No & Yes \\
\hline 11 & Periodic Broadcast & Yes & Yes & Yes \\
\hline 12 & Advantages & $\begin{array}{l}\text { - Adaptable } \\
\text { - Higher bandwidth } \\
\text { - Lesser routing } \\
\text { overhead } \\
\text { - Loop-free-Yes } \\
\text { - Uses Sequences } \\
\text { number to keep the } \\
\text { routing info } \\
\text { updated. }\end{array}$ & $\begin{array}{l}\text { - Support multipath } \\
\text { routing } \\
\text { - Less route discovery } \\
\text { overhead } \\
\text { - Does not require any } \\
\text { HELLO message } \\
\text { exchange } \\
\text { for route maintenance } \\
\text { - Loop-free - Ye } \\
\end{array}$ & $\begin{array}{l}\text { - It is quite suitable } \\
\text { for creating ad } \\
\text { hoc networks } \\
\text { with a small } \\
\text { number of nodes } \\
\text { - }\end{array}$ \\
\hline 13 & Disadvantages & $\begin{array}{l}\text { - Scalability problem } \\
\text { - Takes more time to } \\
\text { build a routing table } \\
\text { - Security - No }\end{array}$ & $\begin{array}{l}\text { - Scalability problem } \\
\text { - High route discovery } \\
\text { latency } \\
\text { - Security - No }\end{array}$ & $\begin{array}{ll}- & \text { it requires a } \\
\text { regular update of } \\
\text { its routing tables }\end{array}$ \\
\hline
\end{tabular}

\section{Table II Comparative Analysis of ADOV, DSR, and DSDV}

\section{Simulation Results and Analysis \\ a. Simulation Environment}

The simulations were executed by using NS2 Simulator. The channel type used in the simulation was wireless and traffic was CBR (UDP). Simulations were done by varying number of nodes from 20, 30, 40,50 to 60 with varying areas $500 * 500$ sq. $\mathrm{m}, 1000 * 1000$ sq. $\mathrm{m}, 1500 * 1500$ sq. $\mathrm{m}, 2000 * 2000 \mathrm{sq} . \mathrm{m}$ and $2500 * 2500$ sq. $\mathrm{m}$ whereas the pause time was kept constant at 10 seconds. The nodes were placed randomly and the simulation time was 150 seconds. Table III gives the simulation parameters used throughout the simulation.

\section{b. Performance Measuring Parameter}

The performance of AODV, DSR and DSDV were measured based on throughput, delay, PDR and PLR. 


\begin{tabular}{|l|l|}
\hline Parameters & Used Simulation \\
\hline Simulator & NS2 \\
\hline Channel Type & Wireless Channel \\
\hline Movement Model & Random Waypoint \\
\hline MAC Layer Protocol & IEEE 802.11 \\
\hline Simulation Time & $200 \mathrm{Sec}$ \\
\hline Simulation Area & $500 * 500, \quad 1000 * 100,1500 * 1500$, \\
& $2500 * 2500$ \\
\hline Number of nodes & $10,2000 * 2000,30,40,50$ \\
\hline Traffic Type & CBR(UDP) \\
\hline Pause Time & $10 \mathrm{sec}$ \\
\hline Maximum Speed & $20 \mathrm{~m} / \mathrm{sec}$ \\
\hline Transmission Range & $250 \mathrm{~m}$ \\
\hline Packet rate & 4packets/sec \\
\hline Protocols Used & AODV, DSR, DSDV \\
\hline Transport Metrics & Throughput, Delay \\
\hline Network Metrics & Packet Delivery, Packet Loss Ratio \\
\hline
\end{tabular}

\section{Table III simulation parameters used throughout the simulation}

\section{a. Throughput}

Throughput is the actual data transfer rate which is defined as a ratio of the successful packet. Throughput is affected due to congestion, packet loss, limited resources and dynamic changes in network topology. Mathematically, it is expressed as follow: -

Throughput $=\quad$ No. of aeuverea packets*packet sue*

\section{b. Delay}

\section{Total duration of simulation}

Delay is the complete time taken to arrive the whole message at the destination node. It is equal to the sum of delays of processing time, transmission time, queuing time and propagation time components of all the links of a path.

c. Packet Delivery Ratio: -

Packet Delivery Ratio (PDR) is the ratio of successfully received packets to the total generated packets.

$P D R=\frac{\text { Total } \text { Received Packets }}{\text { Total generated Packets }} * 100$

d. Packet Loss Ratio: -

Packet Loss Ratio (PLR) is the ratio of lost packets to the successfully received packets by the destination nodes.

$P L R=$ Total generated Packets - Total Received Packets $* 100$ Total Received Packets

The simulation results are shown in the following section in terms of throughput, delay, PDR and PLR depend upon network conditions such as network load and network size. Three communications protocols AODV, DSR and DSDV are considered for the comparison.

a. Network Load Analysis: -

In this analysis, we performed with the varying number of nodes say 10,20,30, 40 and 50 with the pause time, simulation time and network size $10 \mathrm{~s}, 200 \mathrm{~s}$ and $1000 * 1000 \mathrm{sq} . \mathrm{m}$ respectively. Other parameters of the network are as same as described in Table III. The performance plots for throughput, delay, PDR and PLR with varying number of nodes (Network load) as shown in fig 4 (a), (b), (c) and (d) respectively. From fig 4 (a) it is observed that DSR outperforms the AODV and OLSR but it is very close with the OLSR for the higher number of nodes. From fig 4 (b) it is observed that if the number of nodes increases then delay of all protocols high rate of change whereas the delay of DSDV has a very slow rate of change in comparison to other protocols AODV and DSR.

DSR beats AODV and OLSR in terms of PDR and PLR with an increasing number of nodes which is shown in fig 4 (c) and 4 (d) respectively.

b. Network Size Analysis: - In this analysis, the number of nodes varied with $500 * 500 \mathrm{sqm}, 1000 * 1000 \mathrm{sqm}$, $1500 * 1500 \mathrm{sqm}, 2000 * 2000 \mathrm{sqm}$ and $2500 * 2500 \mathrm{sqm}$ whereas the pause time, simulation time and a number of nodes were kept constant at 10 s, 200 s and 20 respectively.

Other parameters of the network are as same as described in Table III. The performance plots varying throughput, delay, PDR and PLR with network size as shown in Fig 5 (a), (b), (c) and (d) respectively. From Fig 5 (a) it is observed that throughput is maximum for OLSR and minimum for AODV as 
increasing network sizes. It is also observed that the throughput of DSDV and DSR are almost same for $1000 * 1000 \mathrm{sqm}$. The delay of DSR increases gradually with an increase in network size as shown in fig 5 (b). The delay is minimum for DSR and maximum for AODV. From fig 5 (c) it is observed that PDR is maximum for OLSR protocol whereas PDR is almost same for AODV and DSR. Similarly, we observed from fig 5 (d) that the PLR is minimum for DSDV whereas the PDR is almost same for AODV and DSR.

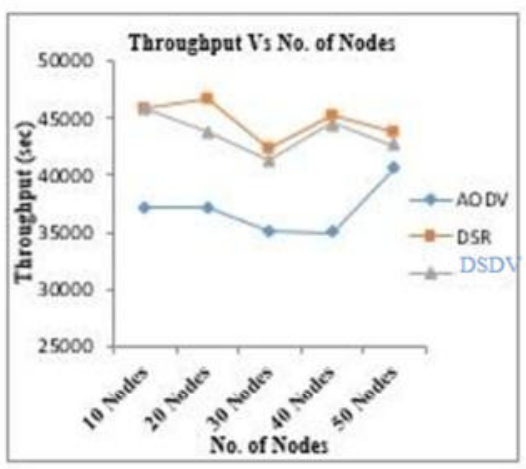

(a)

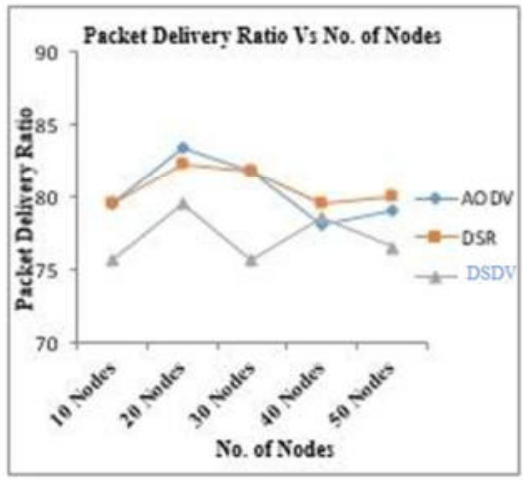

(c)

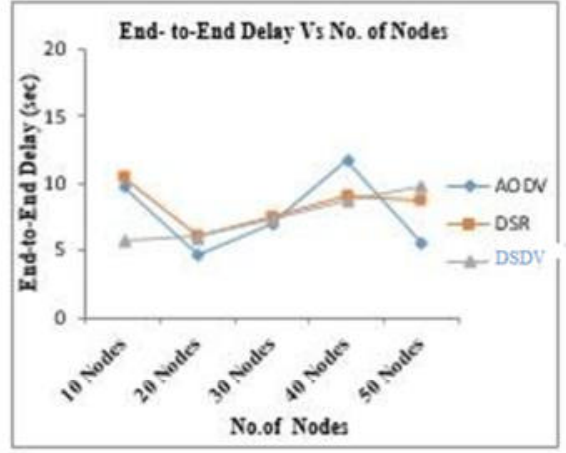

(b)

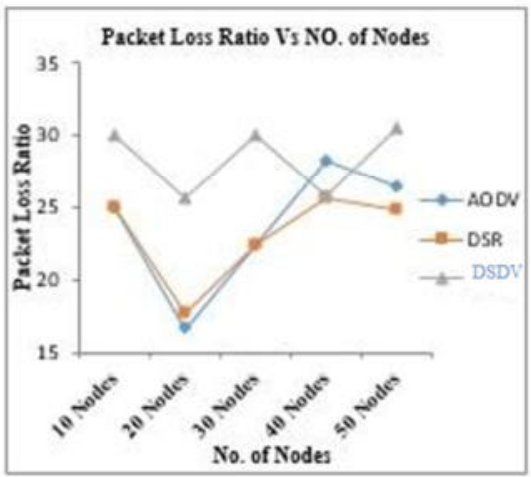

(d)

Figure 1: Performance analysis varying number of nodes (a) Variation of throughput (b) variation of delay (c) Variation of PDR (d) Variation of PLR. 


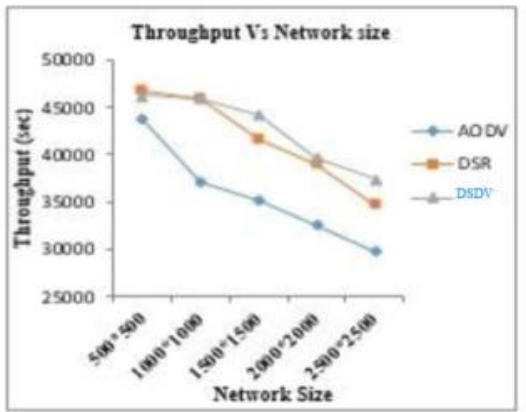

(a)

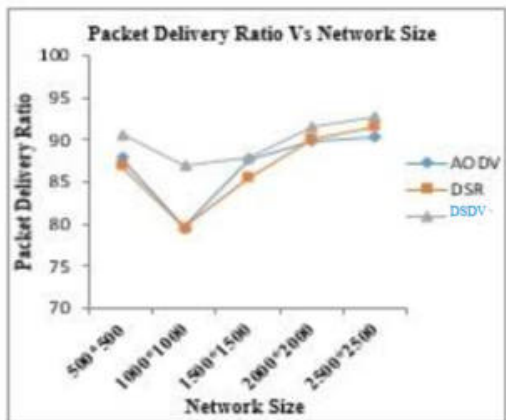

Figure 2: Performance analysis varying network size $(a$ Variation of PDR (d) Variation of PLR.

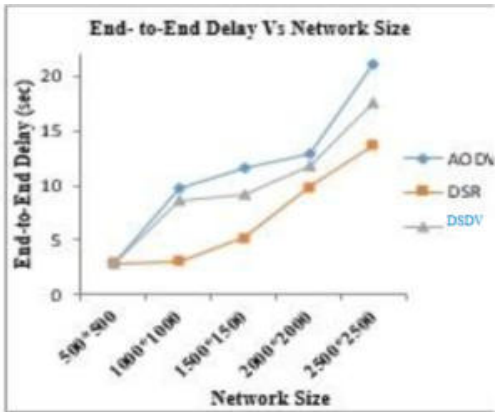

(b)

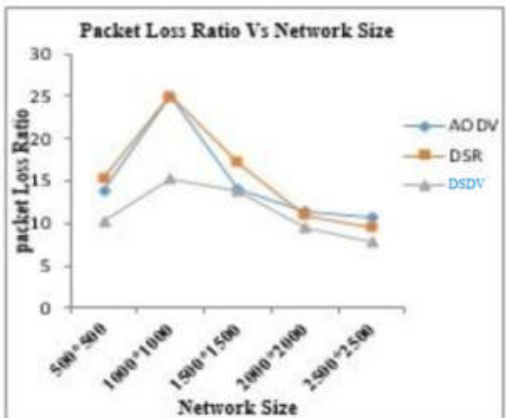

(a) Variation of throughput (b) Variation of delay (c)

\section{CONCLUSION}

In this paper, the performance of routing protocol namely AODV, DSR and DSDV were measured with respect to QoS metrics such as throughput, delay, PDR, PLR in two different scenarios: - varying network load and network size. From the result section V, it can be concluded that DSR outperforms AODV and DSDV in terms of throughput, PDR and PLR with varying the number of nodes and network size. With varying the number of nodes, the throughput of DSR was almost the same as the DSDV after 30 nodes. With varying the network size, the throughput of DSR is also same as the DSDV if the network size is less than $1000 * 1000$ sq. m.

Finally, we can conclude that the overall performance of DSR is better in terms of throughput, PDR, PLR for network load scenario whereas the overall performance of DSDV is better in terms of throughput, PDR, PLR for network size scenario.

Furthermore, modification to the basic DSR and DSDV routing protocols can be possible, so as to make it efficient in large network load and large network size respectively in providing QoS and meet the challenges of mobile ad hoc networks.

\section{References}

A. A. Chavana, P. D. (2016). Performance Analysis of AODV and DSDV Routing Protocol in MANET and Modifications in AODV against Black Hole Attack. 7th International Conference on Communication, Computing and Virtualization, 835-844.

Aggarwal, A. \&. (2014). Performance Analysis of AODV, DSDV and DSR in MANETs. International of Journal of Distributed and Parallel Systems, 167-177.

Ahmed Al-Maashri, M. O.-K. (2006). Performance Analysis of MANET Routing Protocols in the Presence of Self-Similar Traffic. In, Proceedings of the 31st IEEE Conference on Local Computer Networks, 801-806.

Akshai Aggarwal, S. G. (2011). PERFORMANCE ANALYSIS OF AODV, DSDV AND DSR IN MANETS. International Journal of Distributed and Parallel Systems, 167-177.

Akshay Shankar, L. C. (2016, October). Performance Comparison of AODV, DSR, DSDV and OLSR MANET Routing Protocols. International Journal of Engineering Research \& Technology, 5(10), 218-223. Retrieved from http://www.ijert.org

Akshay Shankar, L. C. (2016). Performance Comparison of AODV, DSR, DSDV and OLSR MANET Routing Protocols. International Journal of Engineering and Technical Research.

Ankita Sharma, K. K. (2014). Performance Investigation of AODV, DSR and DSDV MANET Routing Protocols 
using CBR and FTP Traffic. International Journal of Computer Applications, 47-52.

Asma Tuteja, R. G. (2010). Comparative Performance Analysis of DSDV, AODV and DSR Routing Protocols in MANET using NS2. International Conference on Advances in Computer Engineering, 330-332.

Azad, J. A. (2006). Performance Evaluation of Secure on-Demand Routing Protocols for Mobile Ad-hoc Networks. 3rd Annual IEEE Communications Society on Sensor and Ad Hoc Communications and Networks, 971-975.

Bhavyesh Divecha, A. A. (2014). Impact of Node Mobility on MANET Routing Protocols Models. Journal of Digital Information Management, 19-24.

Fahad Taha AL-Dhief, N. S. (2017). MANET Routing Protocols Evaluation: AODV, DSR and DSDV Perspective. MATEC Web of Conferences, 1-6.

G. Shankara Rao, E. J. (2015). Performance Analysis of Manet Routing Protocols - DSDV, DSR,. Global Journal of Computer Science and Technology: E, 15(6), 1-11.

Gulati, M. K. (2014). Performance comparison of mobile Ad Hoc network routing protocols. International Journal of Computer Networks \& Communications , 128-142.

J. Broch, D. M.-C. (1998). A performance comparison of multihop wireless ad hoc network routing protocols. In Proceedings of the 4th Annual ACM/IEEE International Conference on Mobile Computing and Networking, MobiCom, 1-13.

Kumar, J. A. (2016). Study and performance analysis of routing protocol based on CBR. Procedia Computer Science, 23-30.

Mohammad Naserian, K. E. (2017). Routing Overhead Analysis for Reactive Routing Protocols in Wireless Ad Hoc Networks. Wireless And Mobile Computing, Networking And Communications, 2005. (WiMob'2005), IEEE International Conference on, 1-6.

Nilesh Chandra, S. S. (2015). Performance Analysis of AODV, DSR and DSDV in MANETs. International Journal of Computer Applications, 41-43.

Samir R. Das, C. E. (2014). Performance Comparison of Two On-demand Routing Protocols for Ad Hoc Networks. Personal Communications, IEEE, 1-11.

Sandeep Sharma, P. J. (2017). A Comparative Performance Analysis of AODV,DSR and DSDV Protocol for Mobile Ad-hoc Networks. International Journal of Advanced Research in Computer and Communication Engineering, 193-199.

V. Rajeshkumar, P. (2015). Comparative Study of AODV, DSDV and DSR Routing Protocols in MANET Using Network Simulator-2. Specialty Journal of Electronic and Computer Sciences, 35-42. 